\title{
Left Ventricular Oxygen and Substrate Uptake in Chronically Hypoxemic Lambs ${ }^{1}$
}

\author{
MICHIEL DALINGHAUS, JAN WILLEM C. GRATAMA, JAN H. KOERS. ALIE M. GERDING, \\ WILLEM G. ZIJLSTRA, AND JAAP R. G. KUIPERS \\ Beatrix Children's Hospital, Division of Pediatric Cardiology, University of Groningen, Groningen. \\ The Netherlands
}

\begin{abstract}
Myocardial oxygen demand may be increased in chronically hypoxemic lambs because of their increased heart rate. Therefore, we determined whether left ventricular (LV) oxygen supply, oxygen uptake and oxygen demand were proportionally increased in 6-wk-old lambs, after 4 wk of hypoxemia $(n=15)$, as compared with control lambs $(n=14)$. In addition, we determined whether $L V$ glucose, pyruvate, lactate, FFA and ketoacids uptake were altered in hypoxemic lambs, because of alterations in arterial glucose, pyruvate and lactate concentrations, that may occur in hypoxemia. Hypoxemia was induced by the combination of an atrial septal defect and pulmonary stenosis. Arterial oxygen saturation was decreased in hypoxemic lambs $(67 \pm 8$ versus $91 \pm 3 \%, p<$ $0.001), \mathrm{Hb}$ concentration was increased, so that arterial oxygen concentration was similar in both groups of lambs. Myocardial mass $(61 \pm 13$ versus $44 \pm 9 \mathrm{~g}, p<0.001)$ and total myocardial blood flow $(117 \pm 36$ versus $62 \pm 27 \mathrm{~mL}$. $\left.\min ^{-1}, p<0.001\right)$ were increased, mainly due to right ventricular hypertrophy. $L V$ oxygen demand, estimated by the rate pressure product $(2072 \pm 465$ versus $1467 \pm 358$ $\mathrm{kPa} \cdot$ beat $\left.\cdot \mathrm{min}^{-1}, p<0.001\right)$, and oxygen uptake $(723 \pm$ 223 versus $\left.556 \pm 184 \mu \mathrm{mol} \cdot \mathrm{min}^{-1} \cdot 100 \mathrm{~g}^{-1}, p<0.05\right)$ were proportionally increased in hypoxemic lambs. LV oxygen supply increased linearly with oxygen uptake $(r=0.96)$ in all lambs, by adjustments in $L V$ blood flow, which was increased in hypoxemic lambs $(168 \pm 41$ versus $134 \pm 45$ $\left.\mathrm{mL} \cdot \mathrm{min}^{-1} \cdot 100 \mathrm{~g}^{-1}, p<0.05\right)$. The increase in LV oxygen uptake in hypoxemic lambs was proportional to the increase in heart rate $(166 \pm 33$ versus $118 \pm 25$ beats $\left.\min ^{-1}, p<0.001\right)$. Arterial lactate, pyruvate and $\beta$-hydroxybutyrate concentrations were slightly increased in hypoxemic lambs, but LV substrate uptake was practically unaltered as compared with control lambs. FFA and $\beta$-hydroxybutyrate contributed most to $L V$ substrate uptake, whereas the contribution of glucose, pyruvate and lactate was negligible. The total oxygen extraction ratios $(0.45 \pm$ 0.43 versus $0.51 \pm 0.50)$ indicate that approximately $50 \%$ of the fuels for the $L V$ were identified. We conclude that LV oxygen supply is matched to increased oxygen demand in chronically hypoxemic lambs, by the increase in $\mathrm{LV}$ blood flow. $\mathrm{LV}$ substrate uptake is unaltered in hypoxemic lambs; glucose, pyruvate and lactate uptake is negligible, despite an increased arterial pyruvate and lactate concen-
\end{abstract}

Received November 17, 1992: accepted May 3, 1993.

Correspondence: Jaap R. G. Kuipers, M.D., Beatrix Children's Hospital, Division of Pediatric Cardiology, University of Groningen. Oostersingel 59, $9713 \mathrm{EZ}$ Groningen. The Netherlands.

Supported by grants from the Netherlands Organization for Scientific Research NWO) MEDIGON 900-516-089 and from the Netherlands Heart Foundation 87.047).

Presented in part at the Annual Meeting of The Society for Pediatric Research. 1988. Washington, DC. tration. FFA and ketoacid uptake are insufficient to fuel LV oxidative metabolism. (Pediatr Res 34: 471-477, 1993)

\section{Ahbreviations}

LVAVD, left ventricular arteriovenous concentration difference

OER, oxygen extraction ratio

Left ventricular oxygen supply is closely matched to left ventricular oxygen uptake under normal conditions, because the oxygen extraction reserve of the heart is limited. Adjustments in left ventricular blood flow are important to maintain oxygen supply during acute alterations in arterial oxygen saturation or $\mathrm{Hb}$ concentration $(1-7)$.

In chronic hypoxemia, the increased $\mathrm{Hb}$ concentration compensates for the decreased arterial oxygen saturation (8), so that no adjustments in left ver:ticular blood flow would be needed to maintain oxygen supply. In chronically hypoxemic adults native to high altitude, left ventricular blood flow, oxygen supply, and oxygen uptake were lower than in adults at sea level (9). In contrast, in young experimental animals exposed to some form of chronic hypoxemia, left ventricular blood flow and oxygen supply were either similar or increased compared with control animals $(10,11)$, but left ventricular oxygen uptake was not determined in these studies. Because no signs of left ventricular dysfunction are found in chronic hypoxemia, one expects that left ventricular oxygen demand is met by oxygen uptake and that left ventricular blood flow and oxygen supply change in proportion to oxygen uptake. In chronically hypoxemic lambs, heart rate was increased but systemic blood flow was not increased (8). Because heart rate is an important determinant of left ventricular oxygen demand, we hypothesized that left ventricular oxygen uptake would be increased in these lambs and that left ventricular oxygen supply would be increased proportionally by adjustments in the blood flow.

Substrate uptake of the left ventricle in lambs mainly consists of glucose, lactate, fatty acids, and ketoacids (12). In children with cyanotic heart disease, the activity of rate-limiting oxidative enzymes for carbohydrates and fatty acids were similar to that in children with noncyanotic heart disease (13), suggesting that substrate preference of the myocardium is unaltered in chronic hypoxemia. However, substrate uptake may be affected by alterations in substrate supply. Glucose concentration may be increased by impaired insulin release in chronic hypoxemia (14). Glucose supply and uptake by the myocardium was increased during infusion of catecholamines (15). Catecholamine concentrations were either increased or normal in chronic hypoxemia (16-19). In hypoxemic adults native to high altitude, myocardial lactate and pyruvate uptake was increased, and this was linearly 
related to the increased arterial substrate concentrations (20). Therefore, we hypothesized that glucose, pyruvate, lactate, FFA. and ketoacids are the main fuels for the left ventricular myocardium, but that in chronically hypoxemic lambs. glucose, pyruvate, and lactate contribute more to the substrate uptake than they do in control lambs.

This study therefore had a dual purpose. First, we wanted to determine whether left ventricular oxygen demand is increased in lambs after $4 \mathrm{wk}$ of hypoxemia and whether left ventricular oxygen uptake and supply are increased proportionally. Second, we wanted to determine whether glucose, pyruvate, lactate, FFA, and ketoacids mainly fuel the left ventricular myocardium and whether the uptake of glucose, pyruvate, and lactate is increased in chronically hypoxemic lambs.

\section{MATERIALS AND METHODS}

Fifteen chronically hypoxemic and 14 control lambs of mixed breed were studied in the 6th to 7 th wk of life. All hypoxemic lambs underwent surgery before the 10th $d$ of life, whereas control lambs underwent surgery at least $1 \mathrm{wk}$ before the experiment.

Surgical procedures and postoperative care. Anesthesia was induced by $2-3 \%$ halothane in oxygen. The lamb was placed on a warming pad $\left(39^{\circ} \mathrm{C}\right)$, intubated, and ventilated with a mixture of halothane $(0.5-1.5 \%)$, oxygen $(40-60 \%)$, and room air by a Servo Ventilator 900B (Siemens-Elema AB, Solna, Sweden). Analgesia was maintained with piritramide $10-20 \mathrm{mg}$ intramuscularly and lidocaine hydrochloride $\left(5 \mathrm{~g} \cdot \mathrm{L}^{-1}\right)$ was administered locally before each skin incision.

The left thoracic cavity was opened in the 4th intercostal space. Polyvinyl catheters (outer diameter $1.5 \mathrm{~mm}$, inner diameter 1.0 $\mathrm{mm}$ ) were inserted into the ascending aorta through the internal thoracic artery and into the superior vena cava through the internal thoracic vein. The hemiazygos vein was ligated $1-3 \mathrm{~cm}$ from its entrance into the pericardium, and a catheter was advanced toward the heart with its tip placed at the confluence with the coronary sinus. Subsequently, the pericardial sac was opened and catheters were inserted through purse-string sutures into the pulmonary artery, the outflow tract of the right ventricle, and the left atrium. In the lambs that were to be made hypoxemic, an atrial septostomy was performed by means of a $5 \mathrm{~F}$ balloon-tipped Fogarty catheter (American Edwards Laboratories, Santa Ana, CA) that was advanced toward the heart from a pedal vein. After positioning the tip into the left atrium through the foramen ovale, we inflated the balloon with $1.5-2.0 \mathrm{~mL}$ sterile saline solution and rapidly withdrew it into the right atrium, thus tearing the atrial septum. This procedure was repeated 2-3 times. In addition, an inflatable silicone rubber constrictor, inner diameter 8-10 mm (Hazen Everett Co., Teaneck, NJ), was fitted around the main pulmonary artery. The lambs that served as controls underwent the same surgical procedure apart from the atrial septostomy, the constrictor around the pulmonary artery, and the insertion of a right ventricular catheter. In all lambs, an $8 \mathrm{~F}$ polyvinyl catheter was placed to drain the left thoracic cavity. All catheters were tunneled to the left flank $5-10 \mathrm{~cm}$ caudal of the 4 th intercostal space. The thorax was closed in layers and all the catheters, except the one for chest drainage, were filled with a heparin solution $(1000 \mathrm{U} / \mathrm{mL})$. All catheters were sealed and protected in a Teflon pouch that was attached to the skin. The left thoracic cavity was aspirated daily for 4-6 d, then the thoracic drain was removed. Daily, the lambs were weighed and the catheters were refilled with fresh heparin solution. Weekly, each lamb was given iron dextran complex equivalent to $200 \mathrm{mg}$ iron intramuscularly.

Induction of hypoxemia was started 3-5 d after surgery. The constrictor around the pulmonary artery was inflated with sterile saline solution $\left(9 \mathrm{~g} \cdot \mathrm{L}^{-1}\right)$, thus inducing an atrial right-to-left shunt through the atrial septal defect. On the first and second day of inflation, the right ventricular systolic pressure was raised to systemic and suprasystemic levels, respectively. Thereafter, the constrictor was inflated to lower the arterial oxygen saturation to $60-70 \%$. Once this level had been reached, the constrictor was only inflated further to maintain the arterial oxygen saturation within this range.

Experimental protocol. The lambs were allowed to feed until they were separated from their mothers, approximately $3-4 \mathrm{~h}$ before the measurements. The lamb was brought to the study area, placed in a canvas sling, and supported in the upright position. Immediately thereafter, the heparin solution was withdrawn from the catheters and discarded, and the catheters were flushed with sterile $\mathrm{NaCl}$ solution $\left(9 \mathrm{~g} \cdot \mathrm{L}^{-1}\right)$ and connected to pressure transducers. Body temperature was monitored with a rectal temperature probe.

Measurements were obtained when the lamb was quiet and at rest. Oxygen uptake was continuously recorded for $30 \mathrm{~min}$; the values obtained at 15 and $30 \mathrm{~min}$ were used to represent oxygen uptake. Blood pressures were measured every $5 \mathrm{~min}$ in the aorta, pulmonary artery, right ventricle, and the right and left atrium. At 15 and $30 \mathrm{~min}$, blood samples were withdrawn from the aorta, the coronary sinus, and the right ventricle or the pulmonary artery to measure oxygen saturation, $\mathrm{Hb}$ concentration, hematocrit, blood gases, and $\mathrm{pH}$. Additionally, at $30 \mathrm{~min} 7-\mathrm{mL}$ blood samples were withdrawn simultaneously from the ascending aorta and the coronary sinus to measure substrate concentrations and $4 \mathrm{~mL}$ of blood were withdrawn from the ascending aorta to measure catecholamine concentrations. Immediately thereafter, blood flow to the heart and other organs was determined by injecting microspheres into the left atrium, while simultaneously a reference sample was withdrawn from the ascending aorta. At the end of the study, the lambs were killed with an overdose pentobarbital. At autopsy, the position of the catheters was verified and organs were taken out to be processed for measurement of radioactivity.

Measurements and calculations. Oxygen uptake was measured by an open flow-through system by means of a Diaferometer MG 4 (Kipp \& Zonen, Delft, The Netherlands) that was connected to a Micrograph BD 2 recorder (Kipp \& Zonen). Blood pressures were measured by Gould P23 ID transducers (Spectramed Inc., Oxnard, CA) and heart rate was calculated from the phasic aortic pressure tracing. Blood gases were measured on an ABL2 (Radiometer A/S, Copenhagen, Denmark) at $37^{\circ} \mathrm{C}$ and corrected to actual body temperature. Oxygen saturation, $\mathrm{Hb}$ concentration, and hematocrit all were measured in duplicate: oxygen saturation by an OSM2 (Radiometer $\mathrm{A} / \mathrm{S}$ ), Hb concentration by the cyanomethemoglobin method, and hematocrit by the microhematocrit method.

The blood samples that were obtained for measurement of substrate concentrations were immediately divided into two portions. Four $\mathrm{mL}$ were mixed in a tube containing some dried $\mathrm{NaF}$ to prevent glycolysis. Then the sample was deproteinized with perchloric acid, neutralized with $\mathrm{KOH}$ and morpholinopropanesulfonic acid solution, centrifuged, and immediately stored in ice. Glucose, pyruvate, lactate, $\beta$-hydroxybutyrate, and acetoacetate concentrations were measured in triplicate with NADP/NADPH-linked enzymatic methods (21). Pyruvate and acetoacetate concentrations were measured the same day; the other samples were stored at $-20^{\circ} \mathrm{C}$ until measurement. The other $3 \mathrm{~mL}$ of blood were immediately transferred to a chilled tube containing dried $\mathrm{NaF}$ and centrifuged, and the plasma was frozen to $-70^{\circ} \mathrm{C}$. Plasma FFA concentration was determined enzymatically by means of a commercial kit (NEFAC, Wako Chemicals GmbH, Neuss, Germany) (22). FFA concentration in whole blood was calculated by multiplying plasma concentration with $[100$ - hematocrit $(\%)] / 100$.

Blood samples for catecholamine determination were centrifuged at $4^{\circ} \mathrm{C}$, for $10 \mathrm{~min}$. Thrombocyte-poor plasma was transferred to tubes containing glutathione as antioxidant, stored at $-20^{\circ} \mathrm{C}$, and measured within $7 \mathrm{~d}$ by HPLC with electrochemical detection (23). 
Microspheres of $15 \mu \mathrm{m}$ diameter labeled with either ${ }^{141} \mathrm{Ce}$, ${ }^{103} \mathrm{Ru},{ }^{52} \mathrm{Cr}$, or ${ }^{95} \mathrm{Nb}$ (NEN-Trac, DuPont Co., Wilmington, DE) were used. Reference samples were withdrawn from the ascending aorta at a rate $6-7 \mathrm{~mL} \cdot \mathrm{min}^{-1}$, starting just before and ending at least $45 \mathrm{~s}$ after the completion of the microsphere injection. Usually, the withdrawal time was $90 \mathrm{~s}$. The exact withdrawal rate was calculated from the difference of the mass of the syringe before and after obtaining the reference sample and the withdrawal time. Radioactivity was determined in the heart, the brain, and other organs. At autopsy, the heart was weighed and stored in formalin (8\%) for 5-8 d. Subsequently, it was stripped of the great vessels, epicardial fat, and chordae, and divided into atrial and ventricular myocardium. The latter was divided into the free wall of the left and right ventricle and the septum. The brain was divided into left and right hemisphere and brain stem. Each part was weighed and counted separately. Radioactivity measurements were performed with a Beckman 9000 multichannel gamma scintillation counter. Blood flows were calculated from the ratio of radioactivity counts in tissue and reference samples times withdrawal rate of the reference sample by using a software package (24). Blood flows were expressed per $100 \mathrm{~g}$ of tissue. Adequate mixing of microspheres in each lamb was checked by ascertaining that blood flow per $100 \mathrm{~g}$ between left and right cerebral hemisphere did not differ by more than $10 \%$ (25).

Blood oxygen concentration was calculated as the product of $\mathrm{Hb}$ concentration, oxygen saturation, and an oxygen-binding capacity of $1.36 \mathrm{~mL} \cdot \mathrm{g}^{-1}(26)$. The systemic blood flow was the oxygen uptake divided by the arterio-mixed venous oxygen concentration difference. Systemic oxygen supply was the product of arterial oxygen concentration and systemic blood flow. Resistance in a vascular bed was calculated as the difference between mean aortic and mean right atrial blood pressure divided by blood flow per $100 \mathrm{~g}$ to that vascular bed. For each animal, a mean value of all the cardiovascular and hematologic variables was calculated from the data points obtained during the $30 \mathrm{~min}$ of measurement.

The rate pressure product (heart rate times systolic arterial blood pressure) and an estimate of stroke work (stroke volume times systolic arterial blood pressure) were calculated as indices of left ventricular oxygen demand. The LVAVD for oxygen and substrates was calculated as the difference between ascending aortic and coronary sinus concentrations obtained at $30 \mathrm{~min}$. Because the blood sampled from the coronary sinus is mainly derived from the left ventricular free wall (27), we calculated uptake of oxygen and substrates as the product of LVAVD and the blood flow to the free wall of the left ventricle. The OER for each substrate was calculated using the following formula:

$$
\text { OER }=\left(\text { LVAVD }_{\text {subtrate }} / \text { LVAVD }_{\text {oxygen }}\right) \times \text { substrate factor }
$$

The substrate factor is equal to the amount of oxygen required to completely oxidize $1 \mathrm{~mol}$ of substrate: for glucose it was 6 ; pyruvate, 2.5 ; lactate, 3 ; acetoacetate, $4 ; \beta$-hydroxybutyrate, 4.5 ; and $\mathrm{FFA}, 25 \mathrm{~mol} \cdot \mathrm{mol}^{-1}$.

Statistical analysis. Mean and SD were calculated for each variable for each group of lambs. The results in hypoxemic and control lambs were compared by means of an unpaired $t$ test. Multiple linear regression was used to determine whether indices of oxygen demand, oxygen uptake, and supply were linearly related, and whether arterial substrate concentrations and left ventricular substrate uptake were linearly related. The effect of hypoxemia was evaluated by introducing a dummy variable for the experimental animal (28). Significance level was 0.05 for all comparisons.

\section{RESULTS}

General (Table 1). Hypoxemic lambs were slightly younger than control lambs and their body mass was lower. The arterial oxygen saturation was decreased and the $\mathrm{Hb}$ concentration was
Table 1. Cardiovascular variables, systemic oxygen supply and oxygen uptake, $\mathrm{pH}$ and blood gases, and catecholamine concentrations

\begin{tabular}{lcc}
\hline & $\begin{array}{c}\text { Control } \\
(n=14)\end{array}$ & $\begin{array}{c}\text { Hypoxemia } \\
(n=15)\end{array}$ \\
\hline Age $(\mathrm{d})$ & $46 \pm 5$ & $41 \pm 6^{*}$ \\
Body mass $(\mathrm{kg})$ & $12.5 \pm 2.2$ & $10.6 \pm 2.3^{*}$ \\
Oxygen saturation $(\%)$ & $91 \pm 3$ & $67 \pm 8^{*}$ \\
$\quad$ Arterial & $55 \pm 5$ & $39 \pm 10^{*}$ \\
$\quad$ Mixed venous & $102 \pm 11$ & $139 \pm 16^{*}$ \\
Hb concentration $\left(\mathrm{g} \cdot \mathrm{L}^{-1}\right)$ & $127 \pm 22$ & $129 \pm 15$ \\
Arterial oxygen concentration $\left(\mathrm{mL} \cdot \mathrm{L}^{-1}\right)$ & $7.0 \pm 1.9$ & $8.3 \pm 2.2^{*}$ \\
Oxygen uptake $\left(\mathrm{mL} \cdot \mathrm{min}^{-1} \cdot \mathrm{kg}^{-1}\right)$ & $145 \pm 49$ & $182 \pm 73$ \\
Systemic blood flow $\left(\mathrm{mL}^{\prime} \cdot \mathrm{min}^{-1} \cdot \mathrm{kg}^{-1}\right)$ & $118 \pm 25$ & $166 \pm 33^{*}$ \\
Heart rate $\left(\right.$ beats $\left.\cdot \mathrm{min}^{-1}\right)$ & $19 \pm 5$ & $23 \pm 12$ \\
Systemic oxygen supply $\left(\mathrm{mL} \cdot \mathrm{min}^{-1} \cdot \mathrm{kg}^{-1}\right)$ & & \\
Mean blood pressure $(\mathrm{kPa})$ & $9.9 \pm 1.0$ & $10.1 \pm 1.4$ \\
$\quad$ Arterial & $0.5 \pm 0.4$ & $0.9 \pm 0.7$ \\
$\quad$ Right atrial & & \\
Arterial blood gases and $\mathrm{pH}$ & $7.43 \pm 0.04$ & $7.39 \pm 0.04^{*}$ \\
$\quad$ pH & $5.2 \pm 0.6$ & $4.3 \pm 0.7^{*}$ \\
PcO $(\mathrm{kPa})$ & $13.3 \pm 1.8$ & $7.9 \pm 1.3^{*}$ \\
PO$(\mathrm{kPa})$ & $24.5 \pm 2.9$ & $18.5 \pm 3.6^{*}$ \\
Bicarbonate $\left(\mathrm{mmol} \cdot \mathrm{L}^{-1}\right)$ & $1.2 \pm 0.7$ & $2.0 \pm 3.8$ \\
Epinephrine $\left(\mathrm{nmol} \cdot \mathrm{L}^{-1}\right) \dagger$ & $10.9 \pm 9.5$ & $17.9 \pm 26.8$ \\
Norepinephrine $\left(\mathrm{nmol} \cdot \mathrm{L}^{-1}\right) \dagger$ &
\end{tabular}

$* p<0.05$.

$\dagger n=13$ for control lambs: $n=11$ for hypoxemic lambs.

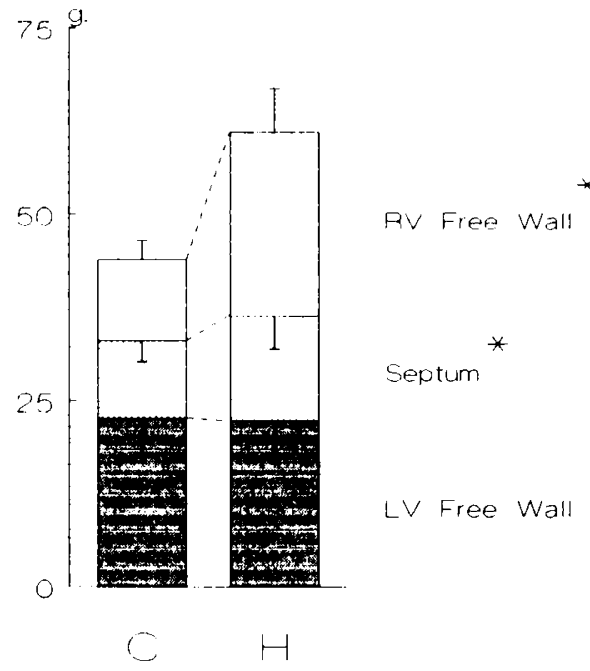

Fig. 1. Myocardial mass and its subdivision into left and right ventricular ( $L V$ and $R V$ ) free wall and septum in control lambs $(C)$ and in lambs after $4 \mathrm{wk}$ of hypoxemia $(H)$. Mean and SD for each ventricular part are shown. ${ }^{*}, p<0.05$.

increased in hypoxemic lambs, so the arterial oxygen concentration was similar to that in control lambs. Heart rate was higher in hypoxemic lambs, but their systemic blood flow was not significantly increased. Although oxygen uptake was increased in hypoxemic lambs, systemic oxygen supply was similar to that in control lambs. Blood pressures were similar in hypoxemic and control lambs. Similarly, we found no difference in epinephrine and norepinephrine concentrations between the two groups of lambs. Hypoxemic lambs had a respiratory compensated metabolic acidosis.

Heart. Myocardial mass was increased in hypoxemic lambs, mainly because of an increased right ventricular mass (Fig. 1). Total myocardial blood flow was increased in hypoxemic lambs $\left(102 \pm 30\right.$ versus $\left.56 \pm 24 \mathrm{~mL} \cdot \mathrm{min}^{-1}, p<0.001\right)$. Per $100 \mathrm{~g}$ of tissue, blood flows to the left ventricle $(p<0.05)$, the septum $(p$ 
$<0.05)$, and the right ventricle $(p<0.001)$ all were significantly increased in hypoxemic lambs (Fig. 2). Left ventricular resistance was similar in hypoxemic and control lambs $(0.06 \pm 0.02$ versus $\left.0.08 \pm 0.02 \mathrm{kPa} \cdot \mathrm{min} \cdot 100 \mathrm{~g} \cdot \mathrm{mL}^{-1}\right)$. The coronary sinus blood in hypoxemic lambs had a lower oxygen saturation (16 \pm 6 versus $25 \pm 10 \%, p<0.01)$ and $\mathrm{Po}_{2}(3.7 \pm 1.1$ versus $4.6 \pm 0.8$ $\mathrm{kPa}, p<0.05)$ than in control lambs. Consequently, the LVAVD for oxygen was maintained at similar levels in hypoxemic and control lambs $\left(4.3 \pm 0.8\right.$ versus $\left.4.1 \pm 0.8 \mathrm{mmol} \cdot \mathrm{L}^{-1}\right)$.

Left ventricular oxygen supply and oxygen uptake were increased in hypoxemic lambs, but left ventricular oxygen extraction was similar in hypoxemic and control lambs (Fig. 3). Left ventricular oxygen uptake per beat was similar in hypoxemic and control lambs $\left(4.5 \pm 1.9\right.$ versus $\left.4.5 \pm 1.0 \mu \mathrm{mol} \cdot 100 \mathrm{~g}^{-1}\right)$. The rate pressure product was increased in hypoxemic lambs $\left(2072 \pm 465\right.$ versus $1467 \pm 358 \mathrm{kPa} \cdot$ beat $\left.\cdot \mathrm{min}^{-1}, p<0.001\right)$. There was a linear relation between the rate pressure product and the left ventricular oxygen uptake $(y=0.26 x+173, r=$ $0.59, p<0.001$ ), and hypoxemia had no effect on this relationship. In contrast, stroke work was similar in hypoxemic and control lambs $(158 \pm 88$ versus $189 \pm 77 \mathrm{kPa} \cdot \mathrm{mL})$, and no relation between stroke work and left ventricular oxygen uptake per beat was found. Left ventricular oxygen supply increased linearly with oxygen uptake (Fig. 4), and hypoxemia had no effect on this relationship.

Arterial pyruvate, lactate, and $\beta$-hydroxybutyrate concentrations were slightly, but significantly, increased in hypoxemic lambs, whereas the other substrate concentrations were similar to that in control lambs (Fig. 5). In addition, the lactate/pyruvate ratio was similar in hypoxemic and control lambs $(18.6 \pm 8.5$ versus $22.7 \pm 13.1$ ). Left ventricular uptake of pyruvate and acetoacetate was slightly different in hypoxemic lambs compared with control lambs, whereas for the other substrates no differences were found (Fig. 5); there was no net lactate production. The OER, however, indicate that the contribution of pyruvate and acetoacetate to left ventricular substrate uptake was only small (Table 2). FFA and $\beta$-hydroxybutyrate were the most important fuels for the left ventricle that we identified, whereas the contribution of glucose, pyruvate, and lactate was small in both hypoxemic and control lambs (Table 2). Left ventricular uptake of ketoacids increased with increasing arterial substrate concentration ( $\beta$-hydroxybutyrate: $y=0.05 x-0.4, r=0.58, p$ $<0.001$; acetoacetate: $y=0.04 x-1.4, r=0.63, p<0.001$ ), whereas for the other substrates such a relation was not found. The OER of all substrates combined adds up to only 0.5 , indicating that we identified approximately $50 \%$ of the fuels for the left ventricle.

\section{DISCUSSION}

In the present study we demonstrated that, in lambs after 4 wk of hypoxemia, left ventricular oxygen supply and oxygen uptake are proportionally increased to meet the increased oxygen demand of the left ventricle. The increase in oxygen demand and oxygen uptake is directly related to the increased heart rate in hypoxemic lambs. We also demonstrated that left ventricular substrate uptake is practically unaltered in hypoxemic lambs compared with control lambs. Despite the increased arterial concentrations of lactate, pyruvate, and $\beta$-hydroxybutyrate in hypoxemic lambs, the uptake of these substrates by the left ventricle is not increased. In addition, glucose, pyruvate, and lactate uptake is negligible, and FFA and ketoacids only supply approximately $50 \%$ of the fuel for the left ventricle in the lambs in our study.

Left ventricular blood flow is high after birth $\left(200 \mathrm{~mL} \cdot \mathrm{min}^{-1}\right.$. $100 \mathrm{~g}^{-1}$ ), but gradually decreases to approximately $50 \%$ of this value in adult sheep $(29,30)$. This is related to a decrease in left ventricular oxygen uptake per unit mass and an increase in $\mathrm{Hb}$ concentration $(26,29,30)$. The increase of the left ventricular blood flow, in our hypoxemic lambs, was not needed to compensate for the decreased arterial oxygen saturation, because the arterial oxygen concentration was similar to that in control lambs. Instead, the increased left ventricular blood flow maintained the left ventricular oxygen supply matched to oxygen uptake (Fig. 4). It is readily apparent from Figure 4 that the matching of left ventricular oxygen supply to oxygen uptake is unaltered in hypoxemic lambs compared with control lambs. The increase of the left ventricular oxygen uptake in hypoxemic lambs was related to their increased heart rate, because per beat both oxygen demand, as estimated by stroke work, and oxygen uptake were similar in hypoxemic and control lambs. Right ventricular blood flow was also increased in hypoxemic lambs, presumably to match right ventricular oxygen supply to an increased right ventricular oxygen demand. The increased heart rate will affect right ventricular oxygen demand in a fashion similar to left ventricular oxygen demand. In addition, the work load imposed on the right ventricle in hypoxemic lambs most likely is increased because of the pulmonary artery banding (31). However, the increase in right ventricular oxygen supply, in these conditions, may be out of proportion to the increase in oxygen demand (31). Thus, the 2-fold increase in blood flow to the ventricular myocardium in hypoxemic lambs can be ascribed in part to the effects of the increased heart rate and, presumably, to the effects of the pulmonary artery banding on right ventricular oxygen demand and supply.

An alteration in myocardial blood flow is the most important mechanism to maintain an adequate myocardial oxygen supply
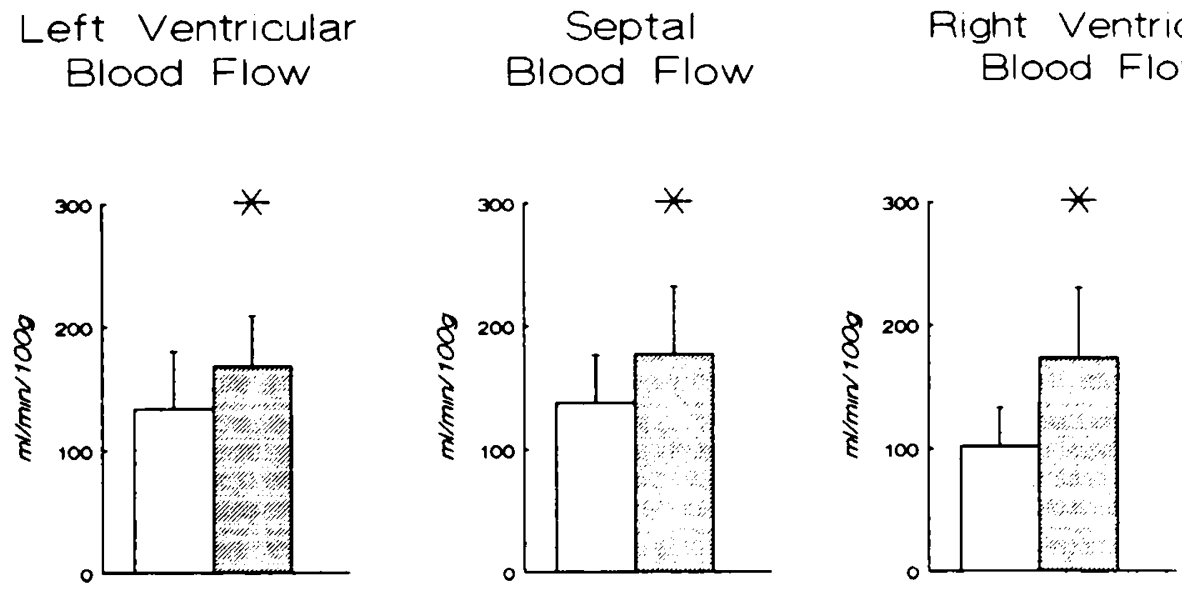

Fig. 2. Blood flow to the ventricular myocardium per $100 \mathrm{~g}$ in control lambs (open bars) and in lambs after 4 wk of hypoxemia (hatched bars). $*, p<0.05$. 


\section{Left Ventricular
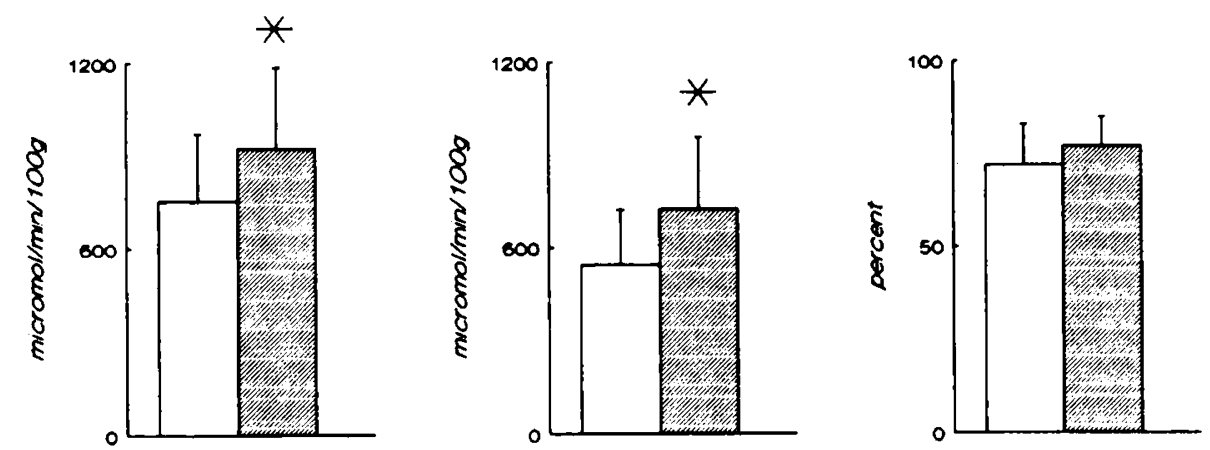

Fig. 3. Left ventricular oxygen supply, oxygen uptake, and oxygen extraction in control lambs (open hars) and in lambs after 4 wk of hypoxemia (hatched hars). ${ }^{*}, p<0.05$.

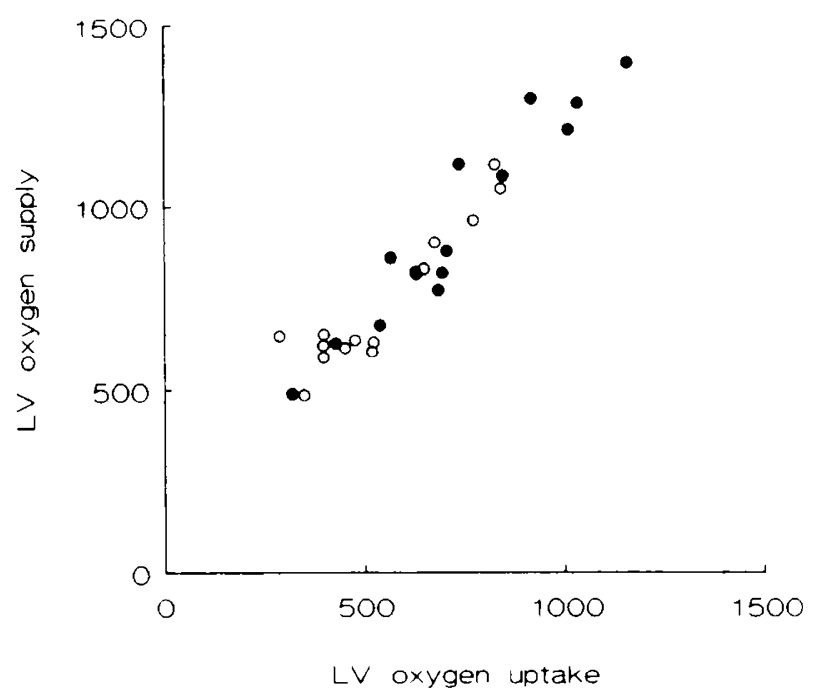

Fig. 4. Left ventricular $\left(L^{\prime}\right)$ oxygen uptake $\left(\mu \mathrm{mol} \cdot \mathrm{min}^{-1} \cdot 100 \mathrm{~g}^{-1}\right)$ is left ventricular oxygen supply $\left(\mu \mathrm{mol} \cdot \mathrm{min}^{-1} \cdot 100 \mathrm{~g}^{-1}\right)$ in control lambs (open circles) and in hypoxemic lambs (black circles). Regression for all animals: $y=1.08 x+158, r=0.96, p<0.001$.

under various pathophysiologic conditions, because the extraction reserve of the heart is limited. Myocardial blood flow is increased to increase oxygen supply in proportion to oxygen uptake (32) or to maintain oxygen supply during (severe) acute hypoxemia or anemia $(1-3,5,6)$. Conversely, myocardial blood flow decreases during acute polycythemia $(1,3,5)$. These adjustments in myocardial blood flow are the result of alterations in vascular tone. In case of acute hypoxemia, the change in resistance reflects the change in vascular tone. However, in case of anemia or polycythemia, a change in resistance reflects the combined result of the alteration in vascular tone and the alteration in whole blood viscosity. For example, in polycythemic dogs coronary resistance increased, but coronary vascular tone decreased to maintain myocardial oxygen supply (3). Similarly, maximal myocardial oxygen supply decreased during progressive polycythemia in dogs, indicating that the viscosity of blood increased relatively more than the oxygen capacity (1). In another set of experiments, we found that whole blood viscosity in hypoxemic lambs was increased compared with control lambs (4.4 versus $3.6 \mathrm{mPa} \cdot \mathrm{s}$, shear rate $100 \mathrm{~s}^{-1}$, unpublished observations). The difference in vascular tone in these conditions can be estimated by the ratio of resistance and whole blood viscosity (3). Because left ventricular resistance in hypoxemic lambs was

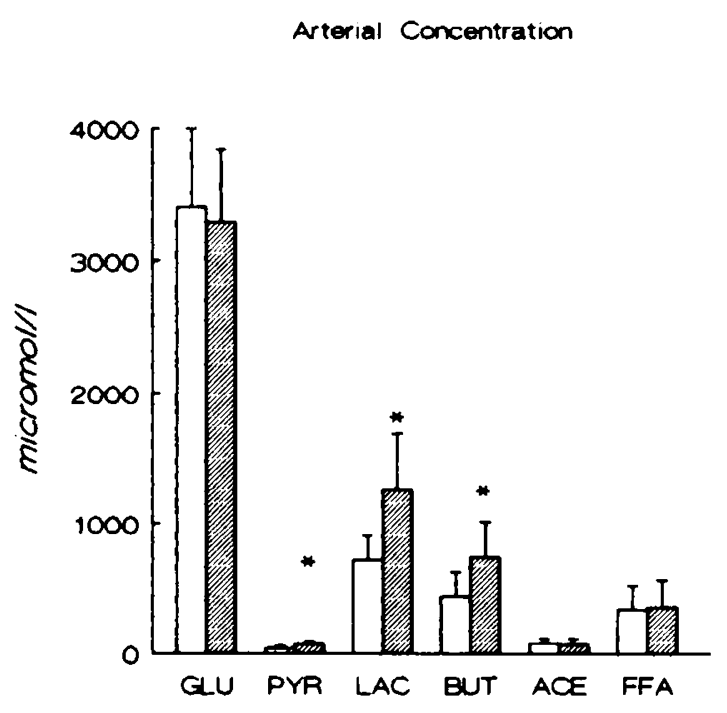

Substrate uptake

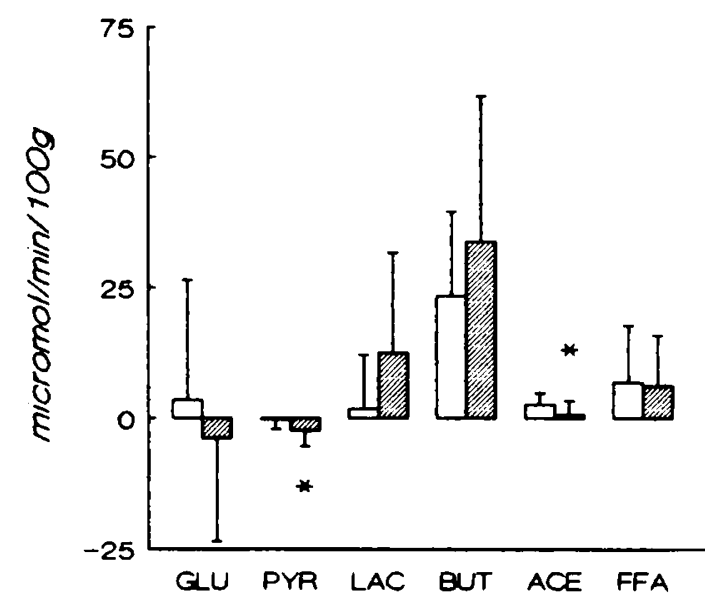

Fig. 5. Arterial substrate concentration and substrate uptake in control lambs (open bars) and in lambs after $4 \mathrm{wk}$ of hypoxemia (hatched hars). $G L U$, glucose; $P Y R$, pyruvate: $L A C$. lactate: $B U T, \beta$-hydroxybutyrate: $A C E$, acetoacetate. ${ }^{*}, p<0.05$. 
Table 2. OER

\begin{tabular}{lcc}
\hline & $\begin{array}{c}\text { Control } \\
(n=14)\end{array}$ & $\begin{array}{c}\text { Hypoxemia } \\
(n=15)\end{array}$ \\
\hline Glucose & $0.02 \pm 0.22$ & $-0.04 \pm 0.20$ \\
Pyruvate & $0.00 \pm 0.01$ & $-0.01 \pm 0.01$ \\
Lactate & $0.01 \pm 0.05$ & $0.05 \pm 0.08$ \\
$\beta$-Hydroxybutyrate & $0.18 \pm 0.09$ & $0.20 \pm 0.11$ \\
Acetoacetate & $0.02 \pm 0.02$ & $0.00 \pm 0.02$ \\
FFA $^{*}$ & $0.28 \pm 0.38$ & $0.19 \pm 0.32$ \\
Total $^{*}$ & $0.51 \pm 0.50$ & $0.45 \pm 0.43$ \\
\hline
\end{tabular}

$* n=11$ for hypoxemic lambs.

approximately 0.8 of that in control lambs and whole blood viscosity 1.25 of that in control lambs, this ratio in hypoxemic lambs was approximately $0.7(0.8 / 1.25)$ of that in control lambs, indicating a decreased vascular tone in the left ventricular myocardium in hypoxemic lambs, and consequently vasodilation. This is corroborated by the observation that, in our hypoxemic lambs, both the oxygen tension and the oxygen saturation of the coronary sinus blood were decreased.

An increase in myocardial blood flow is established at the expense of the coronary flow reserve, unless the microvascular bed has been increased through capillary proliferation. In chronically hypoxemic animals, an increased capillary density has been found in skeletal muscle, brain, and heart $(33,34)$. In all studies, an increased capillary density is found in the right ventricle (3437). However, conflicting results have been reported about the left ventricular capillary density in chronic hypoxemia. In some studies, an increased capillary density of the left ventricle has been found (34), whereas in other studies no effect of hypoxemia on the capillary density of the left ventricle was observed (3537). Because left ventricular capillary density may not be increased in hypoxemic lambs, the increase in flow rate in hypoxemic lambs may be established at the expense of coronary flow reserve.

Arterial lactate and pyruvate concentrations were slightly increased in hypoxemic lambs, which cannot be explained by an increased catecholamine concentration (Table 1). Because the lactate/pyruvate ratio was not increased in hypoxemic lambs, the higher lactate concentration may be related to decreased utilization rather than to increased anaerobic glycolysis. In children with cyanotic heart disease, lactate and pyruvate concentrations were increased after fasting compared with those in noncyanotic subjects (38), possibly through a decreased hepatic uptake of lactate and pyruvate secondary to decreased hepatic perfusion. A decreased hepatic blood flow has indeed been found in chronically hypoxemic lambs (10).

Left ventricular substrate uptake in hypoxemic lambs was practically unaltered compared with that in control lambs, and FFA and $\beta$-hydroxybutyrate were important fuels, whereas the uptake of glucose, pyruvate, and lactate was negligible. Similar results have been obtained in 6-wk-old lambs with and without an aortopulmonary left-to-right shunt in our laboratory (12). A low myocardial glucose, pyruvate, and lactate uptake has also been found in newborn lambs and adult sheep $(29,30)$. In contrast, myocardial lactate and pyruvate uptake increased linearly with arterial substrate concentration in chronically hypoxemic adults, native to high altitude (20). In that study, myocardial oxygen uptake was decreased, which was related to an increased efficiency (9). It was postulated that some adaptation of cellular metabolism might be responsible for these findings. If so, these may take longer to develop than the duration of hypoxemia in our lambs.

The total oxygen extraction ratio was approximately 0.5 in both groups of lambs, indicating that we identified only $50 \%$ of the fuels for left ventricular oxidative metabolism. This may result from the utilization of substrate from endogenous stores or the uptake of substrate that we did not measure. The predominant uptake of fatty acids and ketoacids and the low uptake of glucose and pyruvate in our lambs is compatible with a postabsorptive state (39). In these conditions, the breakdown of glycogen as well as the utilization of glucose through the glycolytic pathway is inhibited (40), so that glucose utilization from endogenous stores is unlikely. The triglyceride pool is another source of endogenous substrate. Zierler (41) suggested that all fatty acids taken up by the myocardium are initially stored in a pool and are used from this pool. In fasted, healthy human subjects, approximately $85 \%$ of the ${ }^{14} \mathrm{C}$-labeled palmitate or oleate taken up by the myocardium underwent oxidation within $30 \mathrm{~min}(42)$. In anesthetized dogs, virtually all the ${ }^{14} \mathrm{C}$-labeled palmitate taken up by the myocardium underwent rapid oxidation (43), and the oxidation of glucose, lactate, and fatty acid uptake accounted for all the oxidative metabolism in resting conditions $(42,44)$. These results suggest that even if all FFA taken up by the myocardium are initially stored in a pool, their use from this pool is rapid. Thus, the low OER in our lambs cannot readily be explained by the utilization of substrates from endogenous stores.

Substantial uptake of substrates that we did not measure will also lead to an OER lower than 1. In another study from our laboratory, we demonstrated that triglycerides also contributed to left ventricular substrate uptake (12). In addition, in sheep large amounts of short-chain fatty acids are produced in the rumen, and acetate is largely delivered to peripheral tissues (45). In resting skeletal muscle, oxidation of acetate accounted for $\approx 20 \%$ of the oxygen uptake, whereas during exercise this decreased to $\approx 5 \%(46)$. Thus, acetate may be an important additional fuel for myocardial oxidative metabolism in lambs.

In summary, we have demonstrated that, in chronically hypoxemic lambs, left ventricular oxygen supply is matched to an increased oxygen demand by adjustments in left ventricular blood flow. The relation between left ventricular oxygen supply and oxygen uptake is unaltered in chronic hypoxemia compared with normoxemia. Left ventricular substrate uptake in chronically hypoxemic lambs is practically unaltered compared with control lambs. We identified that FFA and $\beta$-hydroxybutyrate are the most important substrates taken up by the myocardium, but we speculate that triglycerides and acetate may also contribute to left ventricular substrate uptake.

Acknowledgments. The authors thank Ineke Top-Dalebout and Marchien Velvis (Central Laboratory for Clinical Chemistry, University Hospital, Groningen) for measuring FFA and catecholamine concentrations, and Ineke Wessels for assistance in preparing the manuscript.

\section{REFERENCES}

1. Baer RW, Vlahakes GJ, Uhlig PN. Hoffman JIE 1987 Maximum myocardial oxygen transport during anemia and polycythemia in dogs. Am J Physio 252:H1086-H1095

2. Bernstein D. Teitel DF 1990 Myocardial and systemic oxygenation during severe hypoxemia in ventilated lambs. Am J Physiol 258:H1856-H1864

3. Fan F-C. Chen RYZ. Schuessler GB. Chien S 1980 Effects of hematocrit variations on regional hemodynamics and oxygen transport in the dog. Am J Physiol 238: $\mathrm{H} 545-\mathrm{H} 552$

4. Fisher DJ 1986 Comparative effects of metabolic acidemia and hypoxemia on cardiac output and regional blood flows in unanesthetized newborn lambs. Pediatr Res 20:756-760

5. Holzman IR. Tabata B. Edelstone DI 1986 Blood flow and oxygen delivery to the organs of the neonatal lamb as a function of hematocrit. Pediatr Res 20:1274-1279

6. Sidi D. Kuipers JRG, Teitel DF, Heymann MA. Rudolph AM 1983 Developmental changes in oxygenation and circulatory responses to hypoxemia in lambs. Am J Physiol 245:H674-H682

7. Sidi D. Teitel DF, Kuipers JRG. Heymann MA. Rudolph AM 1988 Effects of $\beta$-adrenergic receptor blockade on responses to acute hypoxemia in lambs. Pediatr Res 23:229-234

8. Teitel DF, Sidi D, Bernstein D, Heymann MA, Rudolph AM 1985 Chronic hypoxemia in the newborn lamb: cardiovascular, hematopoietic, and growth adaptations. Pediatr Res 19:1004-1010

9. Moret P, Covarrubias E, Coudert J, Duchosal F 1972 Cardiocirculatory adaptation to chronic hypoxia. Comparative study of coronary flow myocardial oxygen consumption and efficiency between sea level and high altitude residents. Acta Cardiol 27:283-305

10. Bernstein D. Teitel DF, Sidi D. Heymann MA. Rudolph AM 1987 Redistri- 
bution of regional blood flow and oxygen delivery in experimental cyanotic heart disease in newborn lambs. Pediatr Res 22:389-393

11. Turek Z. Turek-Maischneider M. Claessens RA, Ringnalda BEM, Kreuzer F 1975 Coronary blood flow in rats native to simulated high altitude and in rats exposed to it later in life. Pflugers Arch 355:49-62

12. Gratama JWC. Dalinghaus M. Meuzelaar JJ. Gerding AM. Koers JH. Muskiet FAJ. Kuipers JRG 1992 Myocardial carbohydrate, ketone and fatty acid uptake in conscious lambs with aortopulmonary shunts. Pediatr Res 32: 27-32

13. Dernevik L. Bylund-Fellenius A-C, Ekroth R, Holm J, Idström J-P, Schersten $\mathrm{T} 1988$ Enzymatic activities in heart and skeletal muscle of children with cyanotic and noncyanotic congenital heart disease. Thorac Cardiovasc Surg 36:310-312

14. Hait G. Corpus M. Lamarre FR, Yuan S-H, Kypson J, Cheng G 1972 Alteration of glucose and insulin metabolism in congenital heart disease. Circulation 46:333-346

15. Mehrige ME, Ekas R. Mossberg K. Taegtmeyer H. Gould KL 1987 Catecholamine stimulation, substrate competition, and myocardial glucose uptake in conscious dogs assessed with positron emission tomography. Circ Res 61 (Suppl II): 124-129

16. Bernstein D. Voss E. Huang S. Doshi R. Crane C 1990 Differential regulation of right and left ventricular $\beta$-adrenergic receptors in newborn lambs with experimental cyanotic heart disease. J Clin Invest 85:68-74

17. Johnson TS, Young JB, Landsberg L 1983 Sympathoadrenal responses to acute and chronic hypoxia in the rat. J Clin Invest 71:1263-1272

18. Wolfel EE. Groves BM. Brooks GA. Butterfield GE, Mazzeo RS, Mooree LG, Sutton JR. Bender PR, Dahms TE. McCullough RE, McCullough R, Huang S-Y. Sun S-F. Grover RF. Hultgren HN, Reeves JT 1991 Oxygen transport during steady state submaximal exercise in chronic hypoxia. J Appl Physiol 70:1129-1136

19. Young PM. Rose MS, Sutton JR. Green HJ, Cymerman A. Houston CS 1989 Operation Everest II: plasma lipid and hormonal responses during a simulated ascent of Mt. Everest. J Appl Physiol 66:1430-1435

20. Moret P. Covarrubias E, Coudert J. Duchosal F 1972 Cardiocirculatory adaptation to chronic hypoxia. Comparative study of myocardial metabolism of glucose. lactate, pyruvate and free fatty acids between sea level and high altitude residents. Acta Cardiol 27:483-503

21. Bergmeyer HU 1970 Methoden der Enzymatische Analyse. Verlag Chemic. Weinheim, Germany

22. Demacker PMN, Hijmans AGM, Jansen AP 1982 Enzymic and chemicalextraction determinations of free fatty acids in serum compared. Clin Chem 28:1765-1768

23. Smedes F. Kraak JC. Poppe H 1982 Simple and fast solvent extraction system for selective and quantitative isolation of adrenaline. noradrenaline and dopamine from plasma and urine. J Chromatogr 231:25-39

24. Saxena PR. Schamhardt HC. Forsyth RP. Hoeve J 1980 Computer programs for the radioactive microsphere technique determination of regional blood flow and other hemodynamic variables in different experimental circumstances. Comp Prog Biomed 12:63-84

25. Heymann MA. Payne BD. Hoffman JIE. Rudolph AM 1977 Blood flow measurements with radionuclide-labeled particles. Prog Cardiovasc Dis 20:55-79
26. Lister G, Walter TK. Versmold HT, Dallman PR. Rudolph AM 1979 Oxygen delivery in lambs: cardiovascular and hematologic development. Am J Physiol 237:H668-H675

27. Downing SE, Lee JC. Taylor JFN, Halloran K 1973 Influence of norepinephrine and digitalis on myocardial oxygen consumption in the newborn lamb. Circ Res 32:471-479

28. Zar JH 1984 Biostatistical Analysis. Prentice Hall Inc. Englewood Cliffs. NJ. pp $328-360$

29. Fisher DJ, Heymann MA, Rudolph AM 1980 Myocardial oxygen and carbohydrate consumption in fetal lambs in utero and in adult sheep. Am J Physiol 238:H399-H405

30. Fisher DJ. Heymann MA. Rudolph AM 1981 Myocardial consumption of oxygen and carbohydrates in newborn sheep. Pediatr Res 15:843-846

31. Archie JP. Fixler DE. Ullyot DJ. Buckberg GD. Hoffman JIE 1974 Regional myocardial blood flow in lambs with concentric right ventricular hypertrophy. Circ Res 34:143-154

32. Toorop GP. Hardjowijono R. Dalinghaus M. Gerding AM. Koers JH. Zijlstra WG, Kuipers JRG 1987 Myocardial blood flow and $\mathrm{VO}_{2}$ in conscious lambs with an aortopulmonary shunt. Am J Physiol 252:H68!-H686

33. Eby SH. Banchero N 1976 Capillary density of skeletal muscle in Andean dogs. Proc Soc Exp Biol Med 151:795-798

34. Miller Jr AT. Hale DM 1970 Increased vascularity of brain, heart. and skeletal muscle of polycythemic rats. Am J Physiol 219:702-704

35. Clark DR, Smith P 1978 Capillary density and muscle fiber size in the hearts of rats subjected to simulated high altitude. Cardiovasc Res 12:578-584

36. Manohar M. Parks CM. Bush MA. Tranquilli WJ. Bisgard GE. McPherron TA, Theodorakis MC 1982 Regional myocardial blood flow and coronary vascular reserve in unanesthetized young calves exposed to a simulated altitude of $3500 \mathrm{~m}$ for 8-10 weeks. Circ Res 50:714-726

37. Turek Z, Grandtner M, Kreuzer F 1972 Cardiac hypertrophy, capillary and muscle fiber density, muscle fiber diameter. capillary radius and diffusion distances in the myocardium of growing rats adapted to a simulated altitude of $3500 \mathrm{~m}$. Pflugers Arch 335:19-28

38. Haymond MW. Strauss AW, Arnold KJ. Bier DM 1979 Glucose homeostasis in children with severe cyanotic heart disease. J Pediatrics 95:220-227

39. Opie LH 1986 The Heart. Grune \& Stratton. London, pp 111-135

40. Neely JR. Morgan HE 1974 Relationship between carbohydrate and lipid metabolism and the energy balance of heart muscle. Ann Rev Physiol 36:413-459

41. Zierler KL 1976 Fatty acids as substrates for heart and skeletal muscle. Circ Res 38:459-463

42. Wisneski JA, Gertz EW, Neese RA, Mayr M 1987 Myocardial metabolism of free fatty acids. J Clin Invest 79:359-366

43. Myears DW. Sobel BE. Bergmann R 1987 Substrate in ischemic and reperfused myocardium: quantitative considerations. Am J Physiol 253:H107-H114

44. Spitzer JJ 1974 Effect of lactate infusion on canine myocardial free fatty acid metabolism in vivo. Am J Physiol 226:213-217

45. Bergman NE 1990 Energy contributions of volatile fatty acids from the gastrointestinal tract in various species. Physiol Rev 70:567-590

46. Jarrett IG. Filsell OH, Ballard FJ 1976 Utilization of oxidizable substrates by the sheep hind limb: effects of starvation and exercise. Metabolism 25: 523-531 